\title{
Glinical Analysis of Five Infants with Glycogen Storage Disease of the Heart-Pompe's Disease
}

\author{
Betau Hwang, M.D., C.C. Laura Meng, M.D., \\ Ching-Yuang Lin, M.D., and Hey-Chi Hsu, M.S., D.D.S.*
}

\section{SUMMARY}

Five cases of infant glycogen storage disease of the heart are reported. Their ages ranged from 2 to 7 months. They all presented with generalized hypotonia and respiratory tract infections. Four of the diagnosis were proven by skeletal muscle biopsy and enzymatic assay of alpha-1,4-glucosidase. All 5 infants had clinical signs of cardiac failure, cardiomegaly shown by chest X-ray, short PR intervals, severe left or bi-ventricular hypertrophy shown on electrocardiograms, increased thickness of the right and left ventricular walls and interventricular septum both on M-mode and two-dimensional echocardiograms and angiocardiograms. Four of them died during the follow-up period with a mean age at death of 7.5 months.

\section{Additional Indexing Words:}

Glycogen storage disease Pompe's disease

\footnotetext{
CLYCOGEN storage disease of the heart is a fatal disease caused by the T deposition of glycogen in skeletal and cardiac muscle. It is caused by an inherited deficiency of alpha-1,4-glucosidasc and is an autosomal recessive trait. ${ }^{1)-6)}$

This type of glycogen storage disease was first reported by Pompe and Bischoff in 1932, ${ }^{7,8}$ and has commonly been called Pompe's disease since that time. The clinical symptoms and signs include poor feeding, generalized weakness, failure to thrive, respiratory tract infection, congestive heart failure and early death. ${ }^{1-6)}$ The characteristic electrocardiographic findings consist of short PR intervals, left or bi-ventricular hypertrophy and deep $Q$ waves in the precordial leads. ${ }^{1)-10)}$ Echocardiography has been used to detect the outflow tract obstruction in this particular disease. ${ }^{11)}$ Hemodynamic studies

From the Department of Pediatrics, Veterans General Hospital, National Defense Medical Center, National Yang-Ming Medical College and Department of Pathology, National Taiwan University,* Taiwan.

Address for reprint: Betau Hwang, M.D., Department of Pediatrics, Veterans General Hospital, Taipei, Taiwan, R.O.C. 112.

Received for publication March 6, 1985.

Manuscript revised August 19, 1985.
} 


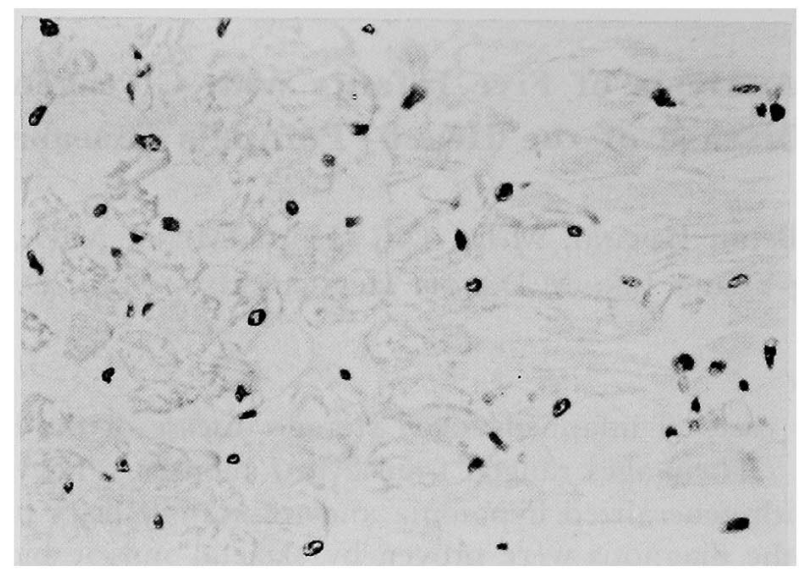

Fig. 1. Light microscopic examination of calf muscle showing severe vacuolar myopathy in the myofibers (indicated by arrows).

and angiocardiography have revealed obstruction of the left and/or right ventricular outflow tract caused by the hypertrophic walls and interventricular septum in some cases. ${ }^{1,10\}-13)}$ Because of the lack of a specific treatment, the patients usually die before 1 year of life in spite of early diagnosis. ${ }^{1,3)}$

To evaluate the clinical features of Pompe's disease in Chinese children, we reviewed the hospital records of 5 infants who were diagnosed as having Pompe's disease in our hospital from July, 1981 to December, 1983.

\section{Materials AND Methods}

From July, 1981 to December, 1983, a total of 795 children with congenital cardiac malformations were admitted to the Department of Pediatrics, Veterans General Hospital for diagnosis and treatment. Five infants who presented with generalized hypotonia and respiratory tract infection were diagnosed as having type II glycogenosis (Pompe's disease) on the basis of clinical presentations and enzymatic assay of alpha-1,4-glucosidase in skeletal muscle biopsy and urinary alpha-1,4-glucosidase levels.

The skeletal muscle specimen was taken from the calf muscle for light and electron microscopic examinations ${ }^{14)}$ and enzymatic assay of alpha-1, 4-glycosidase using 4-methylumbelliferyl-alpha-D-glucoside (Nakarai Chemicals Ltd., Japan) as a substrate. The muscle biopsy revealed severe vacuolar myopathy (Fig. 1) with accumulation of large amounts of PAS-positive material within the myofibers. Ultrastructure showed excessive glycogen beneath the sarcolemma and between the myofibrillar bundles (Fig. 2). Abnormally low levels of alpha-1,4-glucosidase were noted in 4 infants (Table I). 


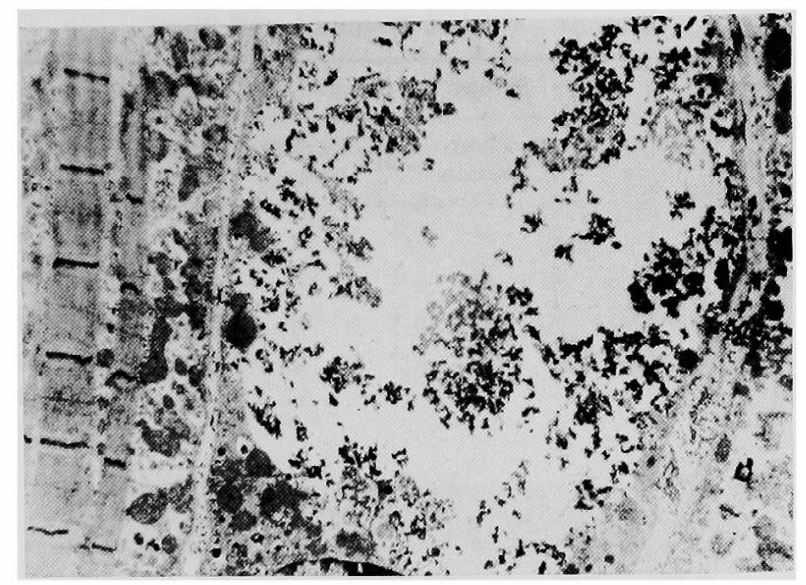

Fig. 2. Electron microscopic examination of calf muscle showing excessive glycogen beneath the sarcolemma and between the myofibrillar bundles.

Table I. Alpha-1, 4-Glucosidase Activity in Calf Muscle (n moles/mg protein/hr)

\begin{tabular}{c|ccccccc}
\hline \multirow{2}{*}{ Case No. } & \multicolumn{7}{|c}{$\mathrm{pH}$ value } \\
\cline { 2 - 8 } & 3.0 & 4.0 & 4.5 & 5.0 & 5.5 & 6.0 & 7.0 \\
\hline 2 & 0.29 & 0.49 & 0.60 & 0.98 & 1.43 & 2.58 & 2.39 \\
3 & 0.40 & 0.50 & 0.40 & 0.87 & 1.28 & 2.58 & 2.39 \\
4 & 0.27 & 0.30 & 0.40 & 0.98 & 1.43 & 2.15 & 2.93 \\
5 & 0.30 & 0.47 & 0.63 & 0.73 & 0.73 & 2.26 & 2.35 \\
\hline Control & $1.09-1.27$ & $4.2-9.0$ & $6.0-8.9$ & $5.4-10.1$ & $4.0-10.8$ & $5.0-8.5$ & $5.4-8.7$
\end{tabular}

By reviewing with hospital records, we were able to evaluate the clinical pictures, chest X-ray, electrocardiograms, echocardiograms, cardiac catheterization data and angiocardiographic findings of these 5 infants.

\section{RESULTS}

1. Age

All 5 infants presented with typical symptoms and signs before 1 year of age. Their ages ranged from 2 to 7 months with a mean age of 4.8 months.

2. Sex

There were 3 boys and 2 girls.

3. Clinical symptoms and signs (Table II)

All 5 infants were admitted due to hypotonia and respiratory tract infection. Three had high fever with rectal temperatures over $39.5^{\circ} \mathrm{C}$ at the time of admission. There were symptoms and signs of congestive cardiac failure 
Table II. Clinical Symptoms and Signs

\begin{tabular}{|c|c|c|c|c|c|c|c|c|c|c|}
\hline \multirow{2}{*}{$\begin{array}{l}\text { Case } \\
\text { No. }\end{array}$} & \multirow{2}{*}{ Sex } & \multirow{2}{*}{$\begin{array}{l}\text { Age at } \\
\text { diagnosis } \\
\text { (months) }\end{array}$} & \multicolumn{6}{|c|}{ Symptoms \& signs } & \multirow{2}{*}{$\begin{array}{l}\text { C/T ratio } \\
\text { chest } X-\text { ray }\end{array}$} & \multirow{2}{*}{$\begin{array}{c}\text { Life } \\
\text { span } \\
\text { (months) }\end{array}$} \\
\hline & & & $\begin{array}{c}\text { Hypo- } \\
\text { tonia }\end{array}$ & Fever & $\begin{array}{l}\text { Pneu- } \\
\text { monia }\end{array}$ & $\mathrm{CHF}$ & $\begin{array}{l}\text { Hepato- } \\
\text { megaly }\end{array}$ & $\begin{array}{l}\text { Cardiac } \\
\text { murmur }\end{array}$ & & \\
\hline 1 & $\mathrm{M}$ & 7 & + & + & + & + & + & + & 0.60 & 12 \\
\hline 2 & $\mathbf{M}$ & 6 & + & + & + & + & + & + & 0.64 & 7 \\
\hline 3 & $\mathrm{M}$ & 3 & + & + & + & + & + & + & 0.69 & 4 \\
\hline 4 & $\mathrm{~F}$ & 2 & + & - & + & + & + & + & 0.62 & alive \\
\hline 5 & $\mathrm{~F}$ & 6 & + & - & + & + & + & + & 0.58 & 7 \\
\hline
\end{tabular}

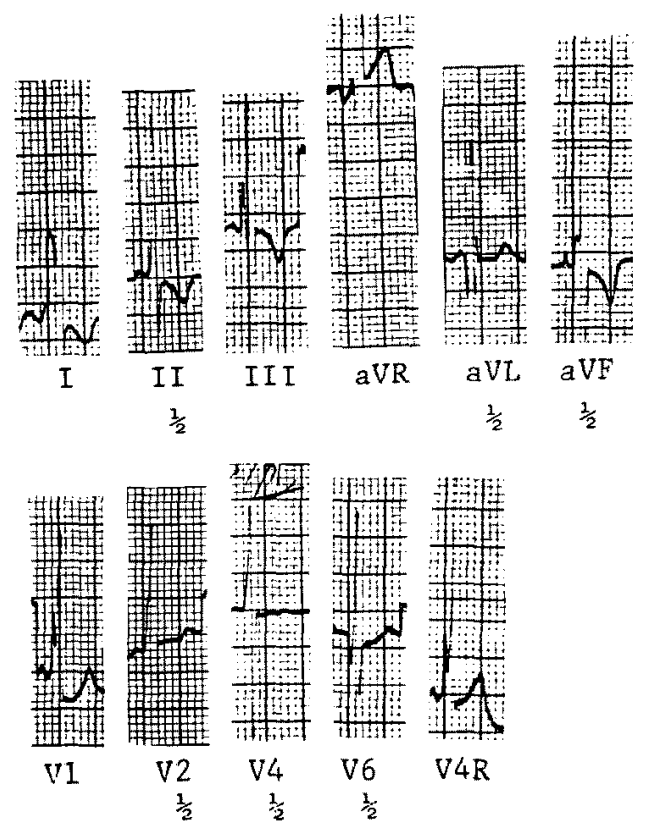

Fig. 3. An electrocardiogram showing the typical findings of short PR interval and tall $R$ waves in leads $I, I I, \mathrm{aV}_{F}, V_{1}$ and $V_{6}$.

including tachypnea, hepatomegaly and cardiomegaly with the cardiac/ thoracic ratio greater than 0.55 in all 5 . Four had a Gr. I-II/VI systolic murmur heard over the left upper sternal border.

4. Electrocardiographic findings

All 5 infants had serial standard electrocardiographic recordings during hospitalization. Each infant had the characteristic electrocardiographic findings of Pompe's disease. Short PR intervals were observed in all the infants, abnormal deep $Q$ waves in leads II, III and $\mathrm{aV}_{\mathrm{F}}$ in 3 infants and in precordial lead $V_{1}$ in 4 infants. The $P R$ intervals ranged from 0.05 to $0.1 \mathrm{sec}$ with a 
Table III. Electrocardiographic Findings

\begin{tabular}{|c|c|c|c|c|c|c|c|c|c|c|c|c|c|}
\hline \multirow{2}{*}{$\begin{array}{l}\text { Case } \\
\text { No. }\end{array}$} & \multirow{2}{*}{$\begin{array}{l}\text { PR/RR interval } \\
\text { in lead II } \\
(\mathrm{sec})\end{array}$} & \multirow{2}{*}{$\begin{array}{c}\text { QRS } \\
\text { axis } \\
\text { (degree) }\end{array}$} & \multicolumn{5}{|c|}{$Q$ wave $(\mathrm{mm})$} & \multicolumn{6}{|c|}{$R$ wave $(\mathrm{mm})$} \\
\hline & & & I & II & III & $a V_{F}$ & $\mathrm{~V}_{6}$ & I & II & III & $a V_{F}$ & $\mathrm{~V}_{1}$ & $V_{6}$ \\
\hline 1 & $0.10 / 0.40$ & +90 & 1 & 2 & 3 & 3 & 8 & 18 & 25 & 28 & 30 & 24 & 52 \\
\hline 2 & $0.08 / 0.36$ & +35 & 0 & 0 & 12 & 2 & 6 & 38 & 28 & 14 & 18 & 19 & 54 \\
\hline 3 & $0.06 / 0.41$ & +40 & 5 & 0 & 0 & 0 & 8 & 34 & 20 & 18 & 30 & 23 & 36 \\
\hline 4 & $0.05 / 0.36$ & -35 & 0 & 0 & 0 & 0 & 0 & 36 & 25 & 4 & 4 & 6 & 33 \\
\hline 5 & $0.08 / 0.42$ & +75 & 0 & 4 & 14 & 10 & 6 & 34 & 46 & 64 & 60 & 15 & 40 \\
\hline
\end{tabular}

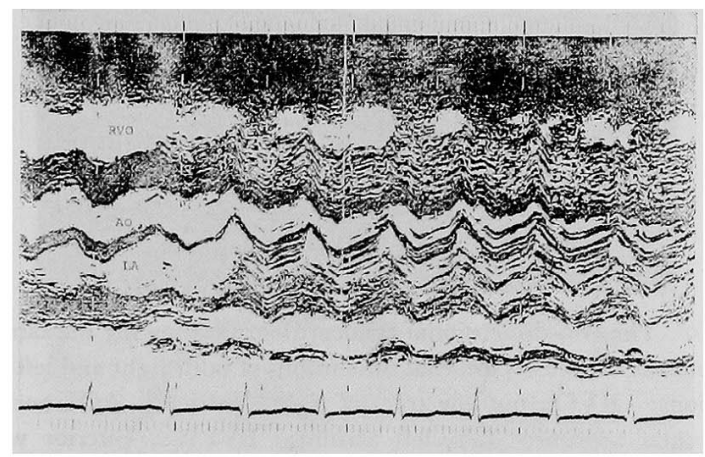

Fig. 4. M-mode electrocardiogram showing the increased thickness of the right and left ventricular walls and interventricular septum. Abbreviations: $\mathrm{RVO}=$ outflow tract of right ventricle; $\mathrm{AO}=$ aorta; $\mathrm{LA}=$ left atrium.

mean of 0.075 sec. When the PR intervals were corrected for heart rate using the formula $P R c=P R m / \sqrt{R R}$, the corrected $P R$ intervals of these 5 infants ranged from 0.083 to $0.180 \mathrm{sec}$ with a mean of $0.159 \mathrm{sec}$. The mean frontal axes of the QRS were within normal limits except for 1 infant in whom there was a left axis deviation of -35 degrees. A tall $\mathrm{R}$ wave in leads I, II, III, $a V_{F}$ and $V_{1}$ (Fig. 3) was noted in all but 1 infant, he had a tall $R$ wave only in leads I, II and $V_{6}$ (Table III).

\section{Echocardiographic findings}

M-mode, two-dimensional and pulsed Doppler echocardiographic studies were performed on all of the infants. The M-mode and two-dimensional echocardiograms showed enormously thickened right and left ventricular walls and interventricular septa (Figs. 4, 5). The internal dimensions of the left and right ventricles were smaller than those of the hearts of normal infants which we reported previously. ${ }^{15)}$ There was no systolic antcrior motion of the anterior mitral valve in any of these 5 infants, A systolic turbulencc was recorded at the right ventricular outflow tract and pulmonary artery in 4 infants by pulsed Doppler echocardiography (Fig. 6). None had systolic 


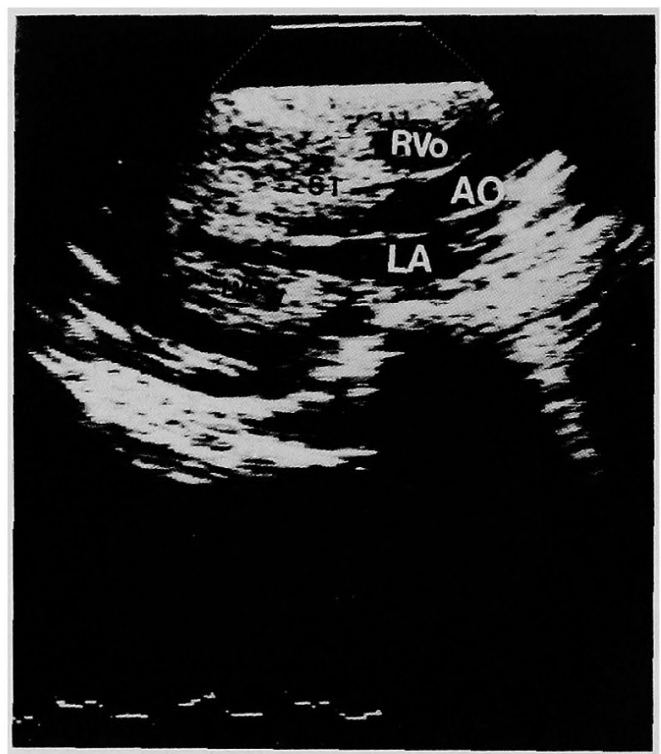

Fig. 5. The two-dimensional echocardiogram showing the same findings as Fig. 4 and the decreased internal dimensions of both right and left ventricles. Abbreviations: $\mathrm{RVO}=$ outflow tract of right ventricle; $\mathrm{AO}=$ aorta; $\mathrm{ST}=$ interventricular septum; LA=left atrium; LVPW=posterior wall of left ventricle.

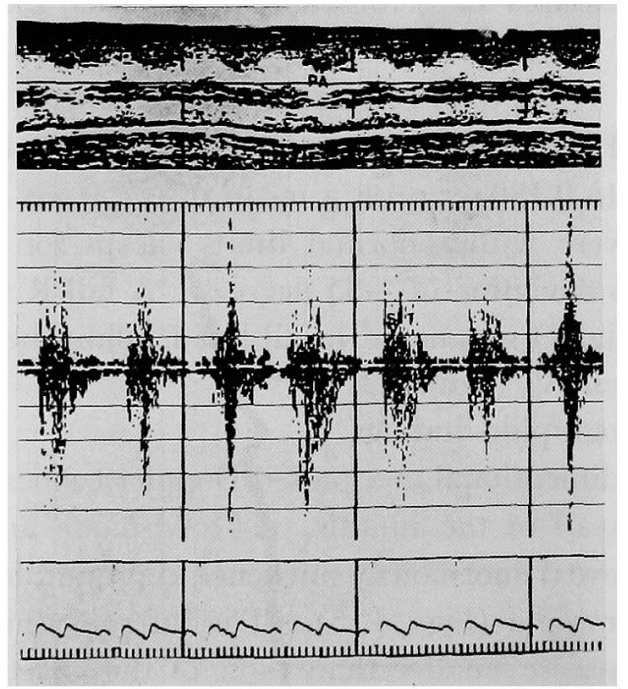

Fig. 6. Pulsed Doppler echocardiogram showing systolic turbulence (ST) in pulmonary artery (PA). 
Table IV. Summary of Cardiac Catheterization Data

\begin{tabular}{c|cccccc}
\hline \multirow{2}{*}{$\begin{array}{c}\text { Case } \\
\text { No. }\end{array}$} & \multicolumn{5}{|c}{ Pressure (mmHg) } \\
\cline { 2 - 6 } & RA a/v/m & RV S/ED & PA S/D/M & BP S/D & LA a/v/m & LV S/ED \\
\hline 1 & $8 / 7 / 6$ & $34 / 9$ & $31 / 13 / 21$ & $104 / 74$ & $10 / 14 / 10$ & $100 / 10$ \\
2 & $7 / 6 / 5$ & $45 / 8$ & $34 / 15 / 23$ & $114 / 84$ & $12 / 16 / 10$ & $100 / 11$ \\
3 & $9 / 7 / 6$ & & & $104 / 74$ & & \\
4 & $7 / 5 / 5$ & & & $90 / 52$ & \\
5 & $8 / 5 / 6$ & $36 / 6$ & $27 / 9 / 17$ & $96 / 70$ & &
\end{tabular}

Abbreviations : $\mathrm{RA}=$ right atrium; $\mathrm{RV}=$ right ventricle ; $\mathrm{PA}=$ pulmonary artery ; $\mathrm{BP}=\mathrm{blood}$ pressure; $\mathrm{LA}=$ left atrium; $\mathrm{LV}=$ left ventricle; $\mathrm{S} / \mathrm{ED}=$ systole/end-diastole $; \mathrm{S} / \mathrm{D} / \mathrm{M}=$ systole/ diastole/mean.

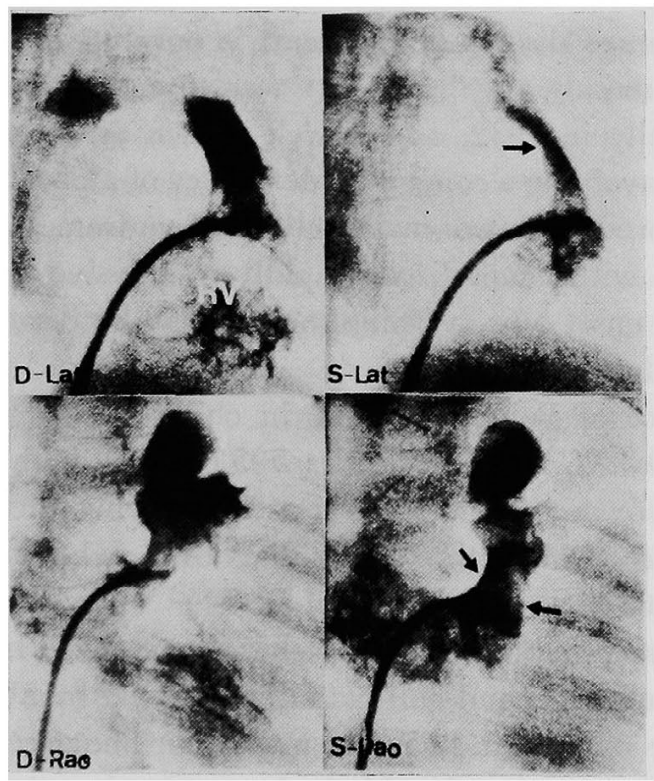

Fig. 7. Right ventriculograms showing a mild degree of narrowing (indicated by arrow) of the right ventricular outflow tract during systole. Abbreviations: $\mathrm{RV}=$ right ventricle; $\mathrm{D}-\mathrm{Lat}=$ lateral view, diastole; S-Lat =lateral view, systole; $\mathrm{D}-\mathrm{Rao}=$ right anterior oblique view, diastole; S-Rao $=$ right anterior oblique view, systole.

turbulence in the aorta.

6. Hemodynamic data and angiocardiography

All 5 infants underwent cardiac catheterization and angiocardiography. Pressure in the right atrium was elevated in all 5. In 3 infants, the catheter was passed into the right ventricle and pulmonary artery and a pressure gradient of 9-11 $\mathrm{mmHg}$ was noted between the outflow and inflow part of the right ventricle (Table IV). Inferior vena cava angiography and right 
ventriculography were performed in 2 and 3 infants respectively. All had enormously thickened right and left ventricular walls and interventricular septa and decreases in the sizes of the right and left ventricular chambers. There was a mild degree of subpulmonic stenosis caused by the hypertrophic septum and right ventricular wall in 4 infants (Fig. 7).

7. Follow-up study

The follow-up period ranged from 1 to 7 months with a mean of 3 months. Four of the infants died during the follow-up period. The age at death ranged from 4 to 12 months with a mean of 7.5 months.

\section{Discussion}

Glycogen storage disease of the heart is one type of generalized glycogenosis affecting mainly the heart. It was first described by Pompe and Bischoff individually in 1932, and is well known as an autosomal recessive inherited disease involving a congenital deficiency of alpha-1,4-glucosidase. ${ }^{1 /-8)}$ This deficiency produces two major clinical syndromes, an infantile type (Pompe's disease) with gencralized, rapidly progressive and fatal disease in infancy and a late onset type, a benign neuromuscular disorder which appears in childhood or adult life.5),16)

The incidence of Pompe's disease in children with congenital cardiac malformations is $0.33 \%{ }^{11}$ In our series, 795 children with congenital cardiac malformations were admitted to our institute during the period from July, 1981 to December, 1983, with 5 being diagnosed as having Pompe's disease, an incidence of $0.63 \%$.

The clinical symptoms and signs include generalized hypotonia, repeated respiratory tract infection and cardiac failure caused by abnormal deposition of glycogen in the skeletal and cardiac muscles. The onset of symptoms and signs usually occurs shortly after birth, but varies between 1 and 6 months after birth. ${ }^{1,-3 /, 9)}$ Four of our patients developed symptoms and signs of generalized hypotonia, cardiac failure and respiratory tract infection by the age of 6 months, the remaining one experienced the same symptoms and signs at the age of 7 months. A positive family history for this particular disease has been reported in the literature ${ }^{1)}$ but was not observed in the present study.

Chest X-rays of patients with Pompe's disease usually demonstrate a variable degree of cardiomegaly and pulmonary atelectasis. ${ }^{1(-3), 6), 9)-12)}$ All 5 patients had similar findings on admission.

The characteristic electrocardiographic findings of Pompe's disease include shorter PR intervals, progressive bi-ventricular or left ventricular hypertrophy, deep $Q$ waves in leads II, III, $a V_{F}$ and the precordial leads, and 
ST-T wave changes. ${ }^{1), 61,9)}$ Left axis deviation of the QRS complex and left and/or right atrial hypertrophy have also been reported. ${ }^{6)}$ In our patients the $\mathrm{PR}$ intervals were shorter with a range of 0.05 to $0.10 \mathrm{sec}$. Bharati et al did electrophysiological studies on patients with Pompe's disease and they suggested that the shorter PR intervals may be related to the enlargement of cells in the atrioventricular node caused by glycogen deposition. ${ }^{17)}$ However, this still needs further investigation and confirmation. The abnormal deep $Q$ waves in leads II, III, $\mathrm{aV}_{\mathrm{F}}$ and the precordial leads indicate myocardial infarction or septal hypertrophy. In our study, abnormal deep $Q$ waves were recorded in leads II, III and $a V_{F}$ in 3 infants and also in $V_{6}$ in 4 infants, respectively. Because of the diffuse deposition of glycogen in the myocardium, the surface electrocardiograms usually indicate right and/or left ventricular hypertrophy by a tall $R$ wave in lead II, III, a $V_{F}, V_{1}$ and/or $V_{6}$. Four of our cases had bi-ventricular hypertrophy and the remaining 1 had left ventricular hypertrophy determined by surface electrocardiography.

M-mode and two-dimensional echocardiography have been very useful noninvasive tools for the measurement of the ventricular walls, internal dimensions and septal thickness and the diagnosis of cardiac structural abnormalities. Marked increases in the thickness of the right and left ventricular walls and the interventricular septum and decreases in both the right and left ventricular dimensions were noted in the 5 infants. These values can be compared with the echocardiographic values in normal Chinese infants and children. ${ }^{15}$ Anterior motion of the anterior mitral valve during systole in Pompe's disease has been reported to be similar to that seen in patients with idiopathic hypertrophic subaortic stenosis. ${ }^{11)}$ However, this phenomenon was not observed in our patients. Pulsed Doppler echocardiography has been introduced as a noninvasive and accurate tool for the localization of cardiac murmurs. ${ }^{18}$ ) A short systolic ejection murmur was heard in 4 of our patients. All of them had a systolic turbulence in the main pulmonary artery and right ventricular outflow tract detected by pulsed Doppler echocardiography. Three of them were shown to have a pressure gradient between the outflow and inflow part of the right ventricle which was confirmed by cardiac catheterization. The pressure gradients were caused by the hypertrophic right ventricular wall and interventricular septum, which were demonstrated by inferior vena cava angiography and/or right ventriculography.

Pompe's disease is a fatal disease and the patients usually succumb during the first year of life. The longest survival reported in the literature is 34 months. ${ }^{19)}$ Four of our patients died during the follow-up period at a mean age of 7.5 months. 


\section{ACKNoWledgments}

The authors wish to express their sincere thanks to Miss B.L. Lin and S.L. Su for preparing this manuscript.

\section{References}

1. Johnson FR: Cardiac hypertrophy in infancy. Glycogen storage disease of the heart. Pediatr Clin North Am 1: 235, 1954

2. Nihill MR, Wilson DS, Hugh-Jones K: Generalized glycogenosis type II (Pompe's disease). Arch Dis 45: 122, 1970

3. Lue HC, Chen JWS, Ghen CL: Primary myocardial diseases in infancy and children. Acta Paediatrica Sinica 9:182, 1968

4. Ninomiya N, Matsuda I, Fukuda S, Iwamasa T, Osame M: Immunohistochemical demonstration of acid alpha-glucosidase in muscle in Pompe's disease. Histochemical J 15: 601, 1983

5. Tanaka K, Shimazu S, Oya N, Tomisaku M, Kusunoki T, Soyama K, Ono E: Muscular form of glycogenosis type II (Pompe's disease). Pediatrics 63: 124, 1979

6. Ehlers KH, Hagstrom JWC, Lukas DS, Redo SF, Engle MA: Glycogen-storage disease of the myocardium with obstruction to left ventricular outflow. Circulation 25: 96, 1962

7. Pompe JC: Hypertrophie idiopathique eu coeur. Ann Anat Path 10: 23, 1933 (cited from 1)

8. Bischoff G: Zum Klinischen Bild der Glycogen-Speicherungs-Krankheit (Glycogenose). Z Kinderheilk 52: 722, 1931-1932 (cited from 1)

9. Caddell $\mathrm{JL}$, Whittemore $\mathrm{R}$ : Observations on generalized glycogenosis with emphasis on electrocardiographic changes. Pediatrics 29: 743, 1962

10. Hohn AR, Lowe CU, Sokal JE, Lambat EC: Cardiac problems in the glycogenosis with specific reference to Pompe's disease. Pediatrics 35: 313, 1965

11. Rees A, Elbl F, Minhas K, Solinger R: Echocardiographic evidence of outflow tract obstruction in Pompe's disease (glycogen storage disease of the heart). Am J Cardiol 37: 1103, 1976

12. Ruttenberg HD, SteidI RM, Carey LS, Edwards JE: Glycogen storage disease of the heart. Hemodynamic and angiocardiographic features in 2 cases. Am Heart J 67: 469, 1964

13. Dickinson DF, Houlsby WT, Wilkinson JL: Unusual angiographic appearances of the left ventricle in 2 cases of Pompe's disease (glycogenosis type II). Br Heart J 41: 238, 1979

14. Lin CY, Hsu HC: Measles and acute glomerulonephritis. Pediatrics 71: 398, 1983

15. Hsieh KS, Hwang BT, Meng CCL: A M-mode echocardiographic study of normal Chinese children. Acta Paediatrica Sinica 23 : 229, 1982

16. Engle AG, Gomez MR, Seybold ME: The spectrum and diagnosis of acid maltase deficiency. Neurology 23: 95, 1973

17. Bharati S, Serratto M, DuBrow I, Paul MH, Swiryn S, Miller RA, Rosebuc Kev N: The conduction system in Pompe's disease. Ped Cardiol 2: 25, 1982

18. Hwang BT, Meng CCL: Doppler echocardiography. Clin Med 10: 57, 1982

19. Rowe RD, Freedom RM, Mehrizi A, Bloom KR: The Neonate with Congenital Heart Disease, 2nd, WB Saunders Co, Philadelphia, London, Toronto, Sydney, p 415, 1981 